\title{
Governance and Water Progress for the Rural Poor
}

\author{
Jami Nelson-Nuñez and Elise Pizzi
}

\begin{abstract}
While the world succeeded in meeting the Millennium Development Goal of halving the number of people without access to improved water sources, many were left behind. As the new Sustainable Development Goals aim to reach universal access by 2030, this article assesses the shortcomings of the MDGs and identifies factors that explain progress for the hardest to reach: the rural poor. The article draws on newly available data on water access by wealth quintiles and finds that rural governance quality is more important for extending water access to the rural poor than to the rich. Government capacity to design and implement policy is particularly important. This article extends the research on inequities in global development progress and the distributive effects of governance quality in development outcomes. KEYwORDs: water, governance, inequality, rural development, Peru.
\end{abstract}

The Millennium Development Goals (MDGs), Which StARTed in 2000 AND ended in 2015, established a global goal to cut in half the proportion of people living without access to drinking water. The MDGs were part of a global effort to eradicate poverty through cooperation among countries, using clear targets, accountability, and a focus on the key components of human development. ${ }^{1}$ The water goal was ambitious and successful; it was met early and was exceeded, helping to contribute to a monumental change that has enabled 2 billion people to gain access to drinking water in the past thirty years. As the world embarks on the new Sustainable Development Goals (SDGs), the task at hand - universal and equitable access to drinking water-necessitates reflection, particularly about the areas and groups of people who were not reached in the MDG era.

Behind the numbers, both globally and for individual countries, huge disparities remain. Eight out of ten people living without access to improved drinking water live in rural areas and nine out of ten people who drink surface waters from lakes and rivers live in rural areas. ${ }^{2}$ In addition, inequities in water access between the rich and the poor exist in all countries, but are particularly worrisome for many developing countries. To understand progress and what is needed to reach 100 percent drinking water access, we ask: What explains the variation in improvement in access to drinking water in rural areas? And what factors are important for extending access to the poor relative to more well-off households? 
The MDGs encouraged progress, but did not stipulate how it should be made. Some countries attained the MDG goal by extending water access to the easiest to reach, using economies of scale to increase access in urban areas and extending access to the wealthiest who could most afford services. Other countries, however, succeeded in their efforts to reach the MDG goal by making progress for poorer populations. For example, in 1995, 55 percent of the poorest Peruvians in rural areas were drinking surface waters without treatment compared to 35 percent of the wealthiest in rural areas. By 2012, Peru had extended substantially more access to improved water across wealth quintiles and closed the gap between the richest and poorest still drinking unimproved water to 22 percent and 26 percent, respectively. In contrast, over the same period Mozambique extended access primarily to the wealthiest fifth of the rural population, improving access rates for the rich from 39 percent to 60 percent while the poorest 40 percent remained stuck at access rates of only slightly more than 25 percent. If the MDG of cutting in half the proportion of the population without access to improved water applied specifically to the population of the rural poor rather than solely to the total national population, the majority of countries would have failed to meet the goal. This "last mile," or the most difficult people and places to reach, merits more attention.

Most analyses of progress in improved water access focus on progress across countries and overlook these inequities that persist behind the statistics of national progress. In this article, we examine which factors affect inequities in access by exploring disparities in improvement in access across classes in rural areas. We use a mixed methodological approach, generating theory based on qualitative research in Peru, and testing it with recently released data from the World Health Organization (WHO) and UN Children's Fund (UNICEF) Joint Monitoring Programme (JMP), which track progress based on quintiles of wealth across seventy-one countries. We examine the role of regime type and governance in expanding drinking water access, including which aspects of governance are most important in extending water access to the rural poor. We find that progress for the rural poor is indeed driven by governance quality. Moreover, the aspects of governance that matter most relate to bureaucratic effectiveness and regulatory strength, rather than accountability or democratic quality.

Our work ties into the greater discussion around the importance of institutional quality for development, reinforcing findings that show that capacity has a more consequential impact on poverty alleviation than the form of government. Our research also has implications for future analyses of progress in the water sector and public services more generally, showing that analyses of different subgroups can yield very different perspectives from those that concentrate on national trends. 


\title{
Understanding Variation in Access to Water in Rural Areas
}

The research examining trends in progress toward drinking water access has focused on national progress rather than gaps in progress. It has largely overlooked subnational disparities in access to water despite the well-known inequalities between rural and urban areas, ${ }^{3}$ across geographic areas, ${ }^{4}$ and among wealth quintiles. ${ }^{5}$ Many analyses have focused on progress at the national level, ${ }^{6}$ but the analysis of rural-urban divides has garnered less attention. ${ }^{7}$ The greatest variation in progress over the MDG period is in rural areas. ${ }^{8}$ Moreover, few studies have focused on the gaps in progress between the poor and wealthier groups. Studies that have explored such inequities have been subnational analyses. ${ }^{9}$ This research speaks to the multiple dimensions of inequality in water access by focusing on access for the rural poor in less developed countries.

In analyzing the arguments and empirical results around water trends, we see a curious disjuncture around the role of governance between the findings of cross-national analyses and the priorities of international actors in the water sector. While governance and the role of government are principal features for international organizations and practitioners, its role in large- $\mathrm{N}$ crossnational analyses of progress has been largely inconsequential. Practitioners in the water and sanitation sector have emphasized the importance of engaging governments and building capacity for sustainable water infrastructure, particularly in rural areas. ${ }^{10}$ For example, the Water and Sanitation Program (WSP) of the World Bank has prioritized poor-inclusive water supply and sanitation:

\begin{abstract}
Weak policies and institutions lead to weak service standards, especially for the poor. The provision of basic services, including safe water and sanitation, is a cornerstone of a functional state. In many countries, however, there is a lack of clarity in institutional mandates, structures, roles, and capacities to provide improved WSS [Water Supply and Sanitation] services. Providing effective technical assistance on service sustainability must be tied to sector governance and to overarching institutional and accountability frameworks. This focus on supporting policy reform and institutional capacity-building is increasingly important as reforms in aid modalities, as well as economic growth, increase the resources channeled through government systems. ${ }^{11}$
\end{abstract}

This attention among the international community to the institutional causes of poor services stands in contrast to the inconsistent findings around governancerelated factors in cross-national analyses. Some found that countries with higher quality governance had higher rates of access, ${ }^{12}$ but others found no role at all. ${ }^{13}$ The role of democratic institutions is equally discordant. While Robert Bain, Rolf Luyendijk, and Jamie Bartram ${ }^{14}$ and Nita Rudra and Nathan Jensen ${ }^{15}$ found no effect, Matthias Krause ${ }^{16}$ found that measures of both democracy and restraints on the executive improved water access. 
The literature on governance and its role in development outcomes more generally is larger and has found that good governance not only improves many aspects of human development, from growth to infant mortality, ${ }^{17}$ but also makes spending more likely to result in effective services. ${ }^{18}$ Good governance is the predictable and regular processes of creating and enforcing rules that structure the interactions among and between people, the management of administration, and the exercise of authority. ${ }^{19}$ While some are wary of the scope of attention that good governance has received, there is a general consensus around the pivotal role of the quality of governance. ${ }^{20}$ However, which aspects of governance are the most important is a matter of debate. ${ }^{21}$

Another debate is whether the "form of government" or the "degree of government" matters more. ${ }^{22}$ Samuel P. Huntington suggests that regime type or the form of rule matters little when the regime cannot provide order and stability. In contrast, others suggest that democracy matters for public service provision and, in particular, that political freedoms and the ability to hold elected leaders to account should have positive effects on human development outcomes. ${ }^{23}$ Others argue that democracy means little if there is no capacity to carry out the decisions of elected officials ${ }^{24}$ and that some dimensions of democracy matter more than others. ${ }^{25}$

Björn Halleröd et al. tested both democracy and government effectiveness on a range of child poverty measures, including access to water, and found that government effectiveness had a more robust effect than democracy, and democracy was insignificant for many outcomes when controlling for government effectiveness in models predicting drinking water deprivation. ${ }^{26}$ These mixed findings may indicate that the missing perspective is not whether governance matters, but which specific aspects matter for whom, for what outcomes, and under which conditions.

\section{The Role of Governance in Water Access for the Rural Poor}

\section{Case Illustration}

Before laying out our hypotheses, we discuss our own field research on rural water systems in Peru that helped to generate our theoretical ideas around the relationships between rural water access and governance. The field research consisted of an analysis of twenty rural communities in the region of Loreto outside of the city of Iquitos. In this tropical context, water is abundant but, without a drinking water system or household treatment system, people drink from rivers, lakes, and streams. The research entailed interviews with community leaders and water committees about their histories with different water systems and their relationships with different government organizations and elected officials as well as their interactions with alternative service providers such as nongovernmental organizations (NGOs) in the area. 
One key obstacle to obtaining and maintaining access to drinking water was the need for external support to construct water systems. The gap in what these communities could afford for construction and expertise and what was required necessitated external support from local governments or NGOs. ${ }^{27}$ Most communities had approached their local government for support. There was no reported difference between political parties in their interest in water projects. Some received promises of funding, and others were able to get support from an NGO. However, the main obstacle was ensuring that funding promises were fulfilled. Communities that had received a promise from the government were stuck in a state of limbo, as they had to pressure the government for action while officials responded that the project was stalled at some bureaucratic stage such as requiring approval or pending bids for construction. In one community, the process was in its second year.

In the six communities with government-built systems, four were nonfunctional, highlighting two further obstacles. Two had been damaged in flooding and required government support to reconnect the systems. In this case, the obstacle was ongoing support when functionality necessitated more than the small fixes that the community was trained to do. One community leader commented that he did not know if the government realized that the system was not working. The two other communities with nonfunctional government-built systems had systems that were fully constructed, but were never officially opened for use due to allegations of corruption. Many reported that the government was more interested in building new projects than keeping existing systems going. In this way, the political incentives from electoral pressure actually undermined the less visible investment of ongoing maintenance in favor of new projects, even if they were likely to fail without support.

In discussing how to prioritize spending toward rural communities, one mayor had explicit goals to extend water access in her municipality, but realized that building new systems required caution. The mayor's concerns stemmed not from the total amount needed to construct a system but from the fact that most new systems, because of their cost and technical requirements, would trigger bureaucratic processes that would slow down implementation and drive up costs. For example, once a system's cost rose above the rough equivalent of $\$ 10,000$, it would need to involve other government agencies such as the Ministry of Finance. The mayor felt pressure to ensure that systems for which the local government allocated money would be successfully completed during her term in office, so investing in (relatively) expensive water systems was a risky endeavor. ${ }^{28}$

Clearly the capacity of government to implement new projects as well as monitor and support existing ones was a key theme throughout the study. Of course, other community-level factors ranging from a lack of technical expertise to mismanagement of funds for chemicals and replacement parts explained why systems broke down. In one area comprising several small communities just outside of the city, broken boreholes dotted the communities. Not one was 
functional, even though all had been built within the past five years by an international religious group, which was no longer around. These issues may appear beyond the scope of governance, but a strong lead role by governments in monitoring systems, providing postconstruction support (including technical and fiscal training), and even liaising with NGOs to encourage better project planning and long-term sustainability are critical roles that governments can play to ensure that rural areas gain and keep access to drinking water.

\section{Hypotheses}

Drawing on these insights from Peru, we posit three hypotheses. Functioning rural water infrastructure is especially reliant on functioning political institutions. In many rural areas around the world, markets and private investment alone are insufficient in meeting drinking water needs. External support to rural communities or households is needed to bridge gaps in affordability of hardware, construction, and technical assistance..$^{29}$ Even when external actors, such as NGOs or religious organizations, contribute toward rural water services, governance still plays a critical role.

The connection between governance and extending water services in rural areas can be thought of as a three-stage process: first, the decision to allocate resources for the construction of new infrastructure; second, the execution of that decision; and, third, the maintenance of water storage and supply systems. For many governments and aid organizations, the focus is on the first two stages, both of which pose serious challenges. Partly because of the focus on infrastructure construction, there are high rates of failure for rural water systems because governments and NGOs invest in systems and move on, leaving communities to manage systems alone. One study by the Rural Water Supply Network found that 36 percent of all rural water systems in sub-Saharan Africa were nonfunctional. Another found that a quarter of systems in rural Tanzania failed in the first two years. ${ }^{30}$ Ongoing functionality requires support such as technical advice and monitoring systems. Together, these three stages necessitate an indirect role for government in creating policies and regulation, in developing information technology infrastructure for monitoring and in building capacity and networks between governments, communities, and nonstate actors to help coordinate and plan. ${ }^{31}$ Echoing the practitioner and international community, we test the effect of governance quality by positing that better governance expands access to water.

\section{Hypothesis 1: Better governance increases access to water in rural areas.}

Given the stages and challenges of extending water access to poor areas, we suspect that the factors that contribute to progress are different for the poor than they are for more wealthy segments of society. When new water projects are designed, the rich are better positioned than others to ensure that their households benefit. They are more likely to be able to capture the resources allocated to 
water provision and infrastructure maintenance by being in positions of power as leaders or as key supporters of such decision-makers. Wealthier citizens are also more likely to be able to purchase property that has better access to water and are more likely to afford infrastructure to create wells and boreholes. Once infrastructure is in place, having more resources affords better management of the systems, as the wealthier may be able to afford the upkeep of pumps and other equipment and pay for support from knowledgeable technicians.

The poor, conversely, are less able to make up for the lack of government provision with self-supply. For the poor, governance that responds to citizens' needs and has the capacity to ensure that projects are completed and maintained are especially important. For these reasons, we posit that governance has a stronger effect on progress for the poorer quintiles than the wealthier quintiles.

Hypothesis 2: In rural areas, better governance has a stronger effect for the poor than the relatively more well-off.

Building on this second hypothesis, we posit that some elements of governance are more important for the poor than others. We focus on three main dimensions of governance: the institutions that determine who governs and the incentives that shape how they govern; the capacity of government employees to implement decisions and monitor outcomes; and the fortitude of institutions that can regulate behavior, of both government and private actors. All three of these aspects of governance have important roles in the extension and ongoing maintenance of water infrastructure and services, but we posit that the latter two (capacity and regulatory strength) are more essential for drinking water outcomes of the rural poor than the first (democratic institutions).

The first challenge of extending water access is spurring investment in services and resources for drinking water systems. This stage is important for the rural poor, as they are less likely than the rich to be able to contribute sufficient funds to infrastructure without external support. The allocation of resources for public goods and services often depends on institutions, but also on the relative sway of different areas and sectors of society. ${ }^{32}$

The second and third stages entail ensuring such decisions take effect and monitoring the efficacy of such efforts. As our cases in Peru illustrate, promising to allocate resources is relatively easy and even the poor may be promised the construction of water supply infrastructure. It is the follow-up and maintenance of those facilities that is particularly challenging for those with less political clout or money to contribute directly. Weak rule of law and the inability to control corruption make it difficult to create rural water systems with quality parts and resilient designs. Infrastructure construction is a well-known opportunity for corruption. ${ }^{33}$ While all stages are difficult and particularly important for the poor, we expect that the aspects of governance that relate to technical and bureaucratic challenges associated with the second and third stages will have a stronger impact in extending access to the poor. 
Hypothesis 3: Bureaucratic capacity and control of corruption have a larger effect on outcomes than voice and accountability.

\section{Data and Measures}

The outcome of interest is the change in access to water in rural areas. We are further interested in how change in access for the poorest quintile (Q1) differ from change in access for the richest quintile (Q5). The data for the dependent variables for this study come from the WHO and UNICEF Joint Monitoring Programme for Water Supply and Sanitation. ${ }^{34}$ The data, compiled from various surveys and censuses, report the share of the population with access to improved water sources within thirty minutes of their house by wealth quintile for seventy-one countries.

Data were available for two points in time, 1995 and 2012, thus constraining our analysis to looking at access based on limited snapshots. Two patterns emerged: first, most countries had made some progress in access to water for all quintiles; and, second, access in both time periods appeared to be higher for the rich. There is a great deal of variation in access and change in access across quintiles and countries, which we seek to address in this article. In our sample, only a quarter of countries cut in half the proportion of the rural poor population without access to improved water during the MDG period. Compared to averages of less developed countries, our sample of seventy-one countries received slightly more aid, had slightly higher linguistic fractionalization, and was slightly more unequal, but our sample was not significantly different on the key variable good governance.

On average, the seventy-one countries in our sample improved rural access to drinking water by 11.5 percent. Table 1 displays the change in water access and the average levels of access for countries in 1995 and 2012. In 1995, on average 60 percent of the rural population had access to improved water sources. The average rate of access increased to 70 percent by 2012. Overall, access for rural populations of all income levels ranged from 19 percent to 98.2 percent in 1995 and from 29.6 percent to 99.2 percent in 2012 . Not every country improved in their water provision in rural areas. In Honduras, water access declined by 13.8 percent (from 83.0 percent to 69.2 percent). In contrast, access in Mongolia expanded by 47.6 percent.

The "last mile problem" suggests that there are gains in access to water that can be made quickly and relatively easily when access is extremely poor. In these cases, there are places that are cost effective-low-hanging fruit for NGOs and governments to rapidly expand water access relatively cheaply. In contrast, the last mile is the most difficult, and NGOs and governments are likely to leave the most difficult challenges - those areas that are extremely remote and difficult to access or where economies of scale are lacking - to the end. Thus, the rate of improvement slows as countries approach full water access. Symptomatic of the 
Table 1 Percentage of Rural Population with Water Access by Quintile

\begin{tabular}{|c|c|c|c|c|c|c|}
\hline \multirow[t]{2}{*}{ Quintile } & \multirow{2}{*}{$\begin{array}{c}\text { Access Level } \\
1995\end{array}$} & \multirow{2}{*}{$\begin{array}{c}\text { Access Level } \\
2012\end{array}$} & \multicolumn{4}{|c|}{ Change in Access 1995-2012 } \\
\hline & & & Mean & $S D$ & Min & $\operatorname{Max}$ \\
\hline Q1 ( & 50.8 & 6 & 11.4 & 16.92 & -27.0 & 57.0 \\
\hline Q2 & 55.41 & 66.27 & 10.86 & 15.52 & -22.0 & 55.0 \\
\hline Q3 & 58.49 & 69.99 & 11.49 & 15.86 & -16.0 & 66.0 \\
\hline Q4 & 62.06 & 73.63 & 11.58 & 14.99 & -14.0 & 38.0 \\
\hline Q5 & 70. & 82 & 12.01 & 14.78 & -14.0 & 60.0 \\
\hline Total population & 59.48 & 70.97 & 11.48 & 13.94 & -13.8 & 47.6 \\
\hline
\end{tabular}

Note: $N=71$.

last mile problem, the countries in our study that started with higher than average (59.0 percent) access improved by only 5.2 percent whereas those with below average rates in 1995 improved by an average of 16.9 percent.

While improvement rates for all quintiles were comparable — between 10.6 percent and 11.7 percent with a correlation of 0.3993 - these averages mask wide variation. In 1995, the average rate of access for the rich was 70 percent, but only 50 percent for the poor. By 2012, 62 percent of the poor had access to water while 82 percent of the rich did. Access rates for the rich and poor were highly correlated across countries - 0.7968 in 1995 and 0.8005 in 2012 - but there was variation in progress and levels of access. For example, in Mexico, access for the rural poor improved by 35 percent. In contrast, the rural rich increased access by only 8 percent, but this was partly because 87 percent of the rural rich already had access in 1995. In contrast, some countries made most of their progress among the rich and saw minimal progress for the poor. Haiti improved access for the rural rich by a respectable 18 percent, from 60 percent in 1995 to 78 percent in 2012. The rural poor were worse off in 2012 than 1995, however, as water access declined 10 percent.

\section{Governance and Rural Governance}

Our key explanatory variables are measures of quality of governance in rural areas, specifically. Governance quality can vary within countries. ${ }^{35}$ Most importantly, depending on the structure and the strength of the state, quality of governance (and reach of the state) is sometimes limited to urban areas, regions near to the capital, or certain groups within society. The result is that rural policy and governance outcomes may be quite different from those in urban areas. High-quality urban government can boost the average governance score even when there is poor rural governance. We therefore consider the effect of rural governance on changes in rural water access. We draw on measures from the International Fund for Agricultural Development (IFAD). ${ }^{36}$ These indicators closely mirror the better-known national-level World Governance Indicators, but 
focus specifically on government performance in creating institutions and policy conducive to enhancing growth and reducing poverty in the rural sector.

The IFAD assessments generate five measures of rural governance, scaled between 0 and 1 . The rural development sector framework scores countries on five main dimensions:

1. Voice and accountability, an index of measures that capture the policy and legal framework for rural organization and the dialogue between the government and rural organizations;

2. Government effectiveness, which measures the allocation and management of resources for rural development;

3. Regulatory quality, an index of three indicators: the health of rural financial markets, the investment climate for rural businesses, and access to agricultural input and product markets;

4. Rule of law, an index that captures rural property rights, including the equity of access to land and agricultural water as well as formal rules regulating water pricing and legal recognition of water user associations; and

5. Control of corruption, which measures accountability, transparency, and control of corruption specifically around issues affecting rural areas.

These reflect our three dimensions of governance of democratic institutions (voice and accountability), capacity (government effectiveness and regulatory quality), and institutions that regulate the behavior or governments and individuals (rule of law and control of corruption). The benefit of the IFAD data is the explicit focus on rural areas. We highlight an important caveat, however, which is that IFAD as an organization is specifically interested in the welfare of the rural poor, and therefore the various indicators capture perceptions of performance that are relevant only for rural development, rather than abstract ratings of how well institutions function. None of the measures include reference to drinking water access and, instead, pertain more generally to agriculture. We argue that the establishment of better governance for agriculture outcomes and rural development influences the outcomes in service delivery for drinking water. Thus, our results should be interpreted with caution and we provide robustness checks using the World Governance Indicators. ${ }^{37}$

The data were available starting in 2004, so scores are averaged from 2004 to 2012. We include an average rural governance score along with indicators of the component parts of rural governance quality. The average rural governance score is 0.54 and range from 0.24 to 0.72 . The IFAD indicators are highly correlated (between 0.73 and 0.86 ), but there is sufficient variation to explore the effect of these different aspects of rural governance.

Finally, we test two democracy measures. We draw on Polity IV to create two measures of democracy that reflect the time and data constraints of our dependent 
variable. First, we look at the average level of democracy from 1995 to 2012. ${ }^{38}$ Second, we create an additive measure of annual democracy scores over the same period. These two measures capture the alternative explanation that the form of government was as important as the quality.

\section{Control Variables}

We also include two types of explanatory variables: economic and demographic variables. Here, we provide a brief description of each category of variable. First, macroeconomic variables include gross domestic product (GDP) per capita, average growth, inequality, and foreign aid. We control for the country's wealth at the beginning of our observation period, in 1995, as an indicator of the starting point for economic development, and the average level of economic growth from 1995 to 2012 as a possible expansion of the availability of resources for the water sector. ${ }^{39}$ On average, the countries in our sample had robust economic growth, averaging 4.5 percent. However, that growth was not obvious among the poorest - on average, the income of the poorest quintile declined slightly from $\$ 5,630$ to $\$ 5,400.40$

Drawing on Rudra and Jensen, we control for inequality because changes in the distribution of income could affect the ability of poorer or richer populations to invest in water services. ${ }^{41}$ We used the United Nations University World Institute for Development Economics Research (UNU-WIDER) dataset of World Income Inequality (WIID3c) to measure the average Gini coefficient and share of wealth held by each quintile of the population. ${ }^{42}$ Gini coefficients range from 0 to 100 , with 0 indicating perfect equality and rising as inequality becomes more pronounced.

Development aid constitutes a small, but potentially important, portion of the total investments in water services. Bain, Luyendijk, and Bartram ${ }^{43}$ apportioned only a small fraction of that total spending to aid, which they estimated to be $\$ 26.6$ billion for $2000-2010$. Despite its relatively small contribution, they also estimated that aid could be responsible for approximately 14 percent of the MDG progress over that decade. Using data from the Organisation for Economic Co-operation and Development (OECD), we look at the per capita total amount of foreign aid given to each country dedicated to water and sanitation over the study's time period. ${ }^{44}$ On average, countries received about $\$ 3.8$ per capita.

Second, we control for demographic factors. Perhaps the most important demographic factor is urbanization. The urbanization rate increased by an average of 6.4 percent, but the change in urbanization rate was as high as 22.0 percent in Haiti. Countries with higher urbanization rates and larger increases in urbanization may prioritize improving access for urban areas, potentially to the detriment of rural communities. We also control for the logged change in population because a growing population increases the demand for drinking water access. 
Finally, we control for the last mile by including the starting point of the level of access to drinking water in 1995. We anticipate a negative effect because, as countries continue to improve, the progress becomes more difficult. Moreover, as countries approach 100 percent coverage, their possible improvement scores are limited.

\section{Modeling}

We use ordinary least squares regression to model determinants of progress in water access in rural areas. To test the effect of different aspects of governance quality across wealth quintiles, we utilize seemingly unrelated regressions (SUR). For these tests, we have five dependent variables - one for the change in drinking water access for each quintile - and expect that changes in water access and the errors associated with modeling changes across quintiles were not independent of each other. Seemingly unrelated regression equations are useful when there are multiple dependent variables and the error terms of equations predicting them are not independent. SUR incorporates weighting into the equations to correct for autocorrelation and estimates the covariance across equations. The result is more efficient estimation and more precise parameter estimates. ${ }^{45}$

\section{Analysis}

We begin by examining the effect of rural governance quality on the total change in rural drinking water from 1995 to 2012. In our first model, presented in Table 2, the initial level of GDP and the initial level of access to drinking water are both significant, but governance measured as the average IFAD score does not matter for the total change in rural access to drinking water. ${ }^{46}$

Table 2 Governance Quality and Total Change in Water Access

\begin{tabular}{lcc}
\hline Variable & \multicolumn{2}{c}{ Total Change in Rural Water Access } \\
\hline Good rural governance (average) & 21.173 & $(18.495)$ \\
GDP per capita 1995 (log) & $4.650^{* * * *}$ & $(1.593)$ \\
Gini change & 0.217 & $(0.199)$ \\
Growth (average) & 0.789 & $(0.839)$ \\
WASH aid (log) & 0.709 & $(2.039)$ \\
Population change (log) & 0.621 & $(1.265)$ \\
Urbanization change & -0.167 & $(0.252)$ \\
Water access 1995 & $-0.426^{* * *}$ & $(0.078)$ \\
Constant & -14.913 & $(21.749)$ \\
\hline
\end{tabular}

Notes: $N=68, R^{2}=0.4337$, standard errors in parentheses. GDP, gross domestic product; Water Supply, Sanitation, and Hygiene (WASH).

$* * * p<0.01 ; * * p<0.05 ; * p<0.1$. 
The general model in Table 2 shows that the level of access in 1995 has a negative and significant effect on change of access (i.e., those countries that had higher access early on expanded access more slowly). This relationship is consistent with the last mile idea - the countries that were already doing well probably had extended access to the easier-to-reach areas and had only the most difficult locales left without drinking water access. Those countries that had very low levels of access to improved water sources could extend access more quickly and more easily by first building infrastructure with better economies of scale and in more accessible areas.

We find no effect for many factors that practitioners and scholars alike have asserted to be important. Among these are the role of development aid for the water and sanitation sector, economic growth, and demographic changes. In further exploration of the role of inequality, we test the average level of inequality across our time period and even change in income among quintiles. There is no correlation between any measure of democracy and progress in access to water, nor is there a significant effect of any specification in regression analysis. ${ }^{47}$

To test our second and third hypotheses, we test systems of five linear regression equations and examined the effects of different aspects of rural governance. Table 3 presents the results of SUR regressions of each governance score on change in water access for wealth quintiles. Each row displays the results of a separately run SUR, with each column displaying the coefficient and standard error for a different dependent variable (the changes in water for that wealth quintile), all using the same control variables as in the base model (Table 2).

Table 3 Dimensions of Rural Governance (IFAD), Democracy, and Change in Water Access by Wealth Quintile

Change in Water Access 1995-2012

(Wealth Quintile)

\begin{tabular}{llccccc} 
Row & Variable & Q5 & Q4 & Q3 & Q2 & Q1 \\
\hline 1 & Average rural governance & 17.765 & 11.647 & $32.404^{*}$ & $47.990^{* *}$ & $53.673^{* *}$ \\
& & $(15.041)$ & $(17.161)$ & $(18.785)$ & $(19.296)$ & $(22.101)$ \\
& $R^{2}$ & 0.5883 & 0.452 & 0.4232 & 0.3471 & 0.3055 \\
2 & Government effectiveness & 12.015 & 16.271 & $31.724^{* *}$ & $40.903^{* * *}$ & $48.335^{* * *}$ \\
& & $(12.121)$ & $(13.846)$ & $(15.008)$ & $(15.499)$ & $(17.535)$ \\
& $R^{2}$ & 0.5863 & 0.455 & 0.4316 & 0.3515 & 0.3178 \\
3 & Regulatory quality & 14.263 & 2.049 & 22.330 & $36.845^{* *}$ & $42.861^{* *}$ \\
& \multirow{2}{*}{$R^{2}$} & $(13.666)$ & $(15.437)$ & $(17.039)$ & $(17.561)$ & $(20.171)$ \\
4 & Rule of law & 0.5862 & 0.4514 & 0.4149 & 0.334 & 0.2941 \\
& & 12.588 & 1.932 & 24.073 & $40.569^{* *}$ & $49.299^{* *}$ \\
& $R^{2}$ & $(14.283)$ & $(16.221)$ & $(17.984)$ & $(18.577)$ & $(21.266)$ \\
& & 0.5842 & 0.4471 & 0.4112 & 0.3308 & 0.2968 \\
\hline
\end{tabular}

continues 


\section{continued}

\begin{tabular}{|c|c|c|c|c|c|c|}
\hline \multirow[b]{2}{*}{ Row } & \multirow[b]{2}{*}{ Variable } & \multirow[b]{2}{*}{ Q5 } & \multicolumn{3}{|c|}{$\begin{array}{c}\text { Change in Water Access 1995-2012 } \\
\text { (Wealth Quintile) }\end{array}$} & \multirow[b]{2}{*}{ Q1 } \\
\hline & & & Q4 & Q3 & Q2 & \\
\hline \multirow[t]{2}{*}{5} & Control of corruption & $\begin{array}{c}15.380 \\
(12.995)\end{array}$ & $\begin{array}{l}21.166 \\
(14.928)\end{array}$ & $\begin{array}{l}29.261^{*} \\
(16.235)\end{array}$ & $\begin{array}{l}35.705 * * \\
(16.768)\end{array}$ & $\begin{array}{r}35.563 * \\
(19.251)\end{array}$ \\
\hline & $R^{2}$ & 0.589 & 0.4591 & 0.4266 & 0.339 & 0.2875 \\
\hline \multirow[t]{2}{*}{6} & Voice \& accountability & $\begin{array}{c}14.523 \\
(13.261)\end{array}$ & $\begin{array}{c}1.484 \\
(15.191)\end{array}$ & $\begin{array}{c}16.257 \\
(16.741)\end{array}$ & $\begin{array}{l}30.978 * \\
(30.978)\end{array}$ & $\begin{array}{l}31.085 \\
(19.911)\end{array}$ \\
\hline & $R^{2}$ & 0.5885 & 0.4514 & 0.4134 & 0.3326 & 0.2816 \\
\hline \multirow[t]{2}{*}{7} & Democracy (average score) & $\begin{array}{c}-0.194 \\
(0.261)\end{array}$ & $\begin{array}{c}0.048 \\
(0.300)\end{array}$ & $\begin{array}{c}0.144 \\
(0.322)\end{array}$ & $\begin{array}{l}-0.027 \\
(0.335)\end{array}$ & $\begin{array}{c}0.023 \\
(0.390)\end{array}$ \\
\hline & $R^{2}$ & 0.5661 & 0.4283 & 0.3988 & 0.3185 & 0.246 \\
\hline \multirow[t]{2}{*}{8} & Democracy (total points) & $\begin{array}{c}-0.009 \\
(0.013)\end{array}$ & $\begin{array}{c}0.001 \\
(0.015)\end{array}$ & $\begin{array}{c}0.007 \\
(0.016)\end{array}$ & $\begin{array}{l}-0.003 \\
(0.017)\end{array}$ & $\begin{array}{l}-0.002 \\
(0.019)\end{array}$ \\
\hline & $R^{2}$ & 0.5736 & 0.4356 & 0.4004 & 0.3071 & 0.2412 \\
\hline
\end{tabular}

Notes: $N=69$. Controls: GDP per capita (log 1995), Gini change; growth (average); Water Supply, Sanitation, and Hygiene (WASH) aid (log); population change (log); urbanization change; water access 1995. Rural Sector Performance Assessments, International Fund for Agricultural Development (IFAD).

$* * * p<0.01 ; * * p<0.05 ; * p<0.1$.

Average governance quality, government effectiveness, regulatory quality, rule of law, and control of corruption all have large and positive effects on the poorest 40 percent, especially the very poorest quintile (Q1), but not on the richest 40 percent. Government effectiveness has a significant effect for the poorest 60 percent of the population, but still does not affect the change in water access for the richest 40 percent (row 2). The magnitude of effect is also large. Our model predicts that a 10.0 percent improvement in government effectiveness would result in an additional 4.8 percent of the rural poor gaining access to water. Regulatory quality improved access by 4.2 percent while a 10.0 percent change in rule of law could increase the level of change in access by 4.9 percent. In contrast, voice and accountability has no reliable effect on change in water access (row 6), a result that bears out in our robustness checks using the World Governance Indicators. ${ }^{48}$

Finally, rows 7 and 8 of Table 3 include measures of democracy from Polity IV. Neither democracy score has any effect on changes in access for drinking water for any quintile of society. Thus, we find more evidence for the role of capacity and regulations that deter corruption than the form of government.

We conclude that rural governance quality matters more for the poor than the rich. In addition, the most important aspects of governance are bureaucratic and regulatory aspects rather than mechanisms (voice and accountability, stability, or democracy) that determine how governments are selected, monitored, and replaced. These latter aspects of governance might be most important 
in making policy, including policies that are inclusive of the poor. The key factors for implementing these policies - control of corruption and government effectiveness - had more explanatory power in determining progress for the poor, implying that progress is more likely a function of capacity than political pressure or accountability structures.

\section{Conclusion}

Worldwide access to safe drinking water has expanded dramatically in the past thirty years, yet there is ample reason to be concerned about the equity of access. In this article, we explore the factors that facilitate improvements in access for rural areas generally and, more specifically, across different socioeconomic classes. We employ a mixed methodological approach, using qualitative analysis to derive our theories and large-N analysis of progress across countries to test our ideas. Our work centers around a dissonance between the emphasis on governance among international actors in the water sector and null findings in academic research on the impact of governance on progress. We find that one likely explanation for this incongruence is that certain aspects of governance matter, but not equally among all groups. Our results suggest that government effectiveness, regulatory quality, and rule of law in rural areas have the most robust effects on expanding water access specifically for the rural poor. While aspects of governance associated with democratic quality, voice, and accountability may matter for development outcomes generally, they are perhaps less critical for the creation and maintenance of water provision infrastructure for the rural poor. Those who are more well-off may have the political clout or resources to coordinate access for their community or arrange private supply, but the poor often need support from the civil service and bureaucracy. These findings contribute to a line of inquiry that seeks to tease apart how various aspects of governance matter for particular groups and outcomes.

This project is motivated by the shift from the MDG era, which encouraged progress generally, to the new SDG era, which seeks to address inequities in progress. Where the MDGs resulted in expanding water access for the populations of less developed countries overall, the SDGs, by targeting universal access, place equity concerns at the forefront. Rather than expanding public services to simply make progress, the new challenge is the equitable provision of services. This shift implies a need for reflection on the last mile - the hardest populations to serve. In contrast to prior research that analyzed national progress in drinking water access, we shift the analysis to the urban-rural divide and to inequalities across wealth quintiles.

Our research provides a first cut at exploring differences in water access for wealth quintiles across countries, but there are limitations. We make use of limited and new data on progress across quintiles, but in doing so we have limited observations of seventy-one countries' progress from 1995 and 2012. As a result, 
we are limited in assessing nonlinear trends, disruptions, or more nuanced yearon-year changes and causal effects. Future analyses may benefit from the growing availability of data that are representative at subnational levels. Given the limitations of the currently available data, we urge readers to treat our results with caution and hope that they provoke further inquiry into the differences in access and patterns of change in access to water-and other development goals such as improved sanitation and open defecation rates - across wealth quintiles.

\section{Notes}

Jami Nelson-Nuñez is an assistant professor in the Department of Political Science at the University of New Mexico. Her research interests include the politics of service provision in decentralized contexts, progress in access to drinking water and improved sanitation, and interactions between local governments and NGOs in human development.

Elise Pizzi is an assistant professor of political science at the University of Iowa and an affiliate of the Water Sustainability Initiative. She studies distributive politics in developing countries with a focus on drinking water provision and rural development. Her research also examines public goods provision and rural governance in China.

1. Sakiko Fukuda-Parr, "Millennium Development Goals: Why They Matter," Global Governance 10, no. 4 (2004): 395-402.

2. World Health Organization (WHO) and the United Nations Children's Fund (UNICEF). "Progress on Sanitation and Drinking Water - 2015 Update and MDG Assessment." Geneva, Switzerland, 2015.

3. Robert E.S. Bain, James Wright, Elizabeth Christenson, and J.K. Bartram, "Rural: Urban Inequalities in Post 2015 Targets and Indicators for Drinking-Water," Science of the Total Environment 490 (15 August 2014): 509-513.

4. Betsy Eagin and Jay P. Graham, "A Study of Water and Sanitation Access Trends in Peru: Where Do Inequities Persist?" Journal of Water Sanitation and Hygiene for Development 4, no. 3 (2014): 499-508.

5. Hong Yang, Robert Bain, Jamie Bartram, Stephen Gundry, Steve Pedley, and James Wright, "Water Safety and Inequality in Access to Drinking-water Between Rich and Poor Households," Environmental Science and Technology 47, no. 3 (2013): 1222 1230.

6. Ben C. Arimah, "What Drives Infrastructure Spending in Cities of Developing Countries?" Urban Studies 42, no. 8 (2005): 1345-1368; Robert Bain, Rolf Luyendijk, and Jamie Bartram, "Universal Access to Drinking Water: The Role of Aid," Working Paper No. 2013/88 (United Nations University World Institute for Development Economics Research [UNU-WIDER], Helsinki: September 2013); Celine Dondeynaz, César Carmona-Moreno, and José Joaquín Lorente, "Analysing Inter-relationships Among Water, Governance, Human Development Variables in Developing Countries," Hydrology and Earth System Sciences 16, no. 10 (2012):3791-3816; Amanda Murdie, Help or Harm: The Human Security Effects of International NGOs (Stanford: Stanford University Press, 2014); Nita Rudra and Nathan M. Jensen, "Openness and the Politics of Potable Water," Comparative Political Studies 44, no. 6 (2011): 771-803. 
7. For exceptions, see Sasidaran Gopalan and Ramkishen S. Rajan, "Has Foreign Aid Been Effective in the Water Supply and Sanitation Sector? Evidence from Panel Data," World Development 85 (September 2016): 84-104; Léonce Ndikumana and Lynda Pickbourn, "The Impact of Foreign Aid Allocation on Access to Social Services in SubSaharan Africa: The Case of Water and Sanitation," World Development 90 (February 2017): 104-114.

8. Alexandra Fehr, Murat Sahin, and Matthew C. Freeman, "Sub-national Inequities in Philippine Water Access Associated with Poverty and Water Potential," Journal of Water Sanitation and Hygiene for Development 3, no. 4 (2013): 638-645; Rachel L. Pullan, Matthew Freeman, Peter Gething, and Simon Brooker, "Geographical Inequalities in Use of Improved Drinking Water Supply and Sanitation Across Sub-Saharan Africa: Mapping and Spatial Analysis of Cross-sectional Survey Data," PLOS Medicine 11, no. 4 (2014): e1001626.

9. Akosua Sarpong Boakye-Ansah, Giuliana Ferrero, Maria Rusca, and Pieter van der Zaag, "Inequalities in Microbial Contamination of Drinking Water Supplies in Urban Areas: The Case of Lilongwe, Malawi," Journal of Water and Health 14, no. 5 (2016): $851-863$.

10. Harold Lockwood and Stef Smits, Supporting Rural Water Supply: Moving Towards a Service Delivery Approach (Warwickshire: Practical Action, 2011).

11. Water and Sanitation Program (WSP), "Supporting Poor-inclusive WSS Sector Reform-WSP," http://wsp.org/content/supporting-poor-inclusive-wss-sector-reform, accessed 16 August 2017.

12. Karen Bakker, Michelle Kooy, Nur Endah Shofiani, and Ernst-Jan Martijn, special section, "Governance Failure: Rethinking the Institutional Dimensions of Urban Water Supply to Poor Households," World Development 36, no. 10 (October 2008): 1891-1915; Björn Halleröd, Bo Rothstein, Adel Daoud, and Shalien Nandy, "Bad Governance and Poor Children: A Comparative Analysis of Government Efficiency and Severe Child Deprivation in 68 Low- and Middle-income Countries," World Development 48 (2013): 19-31; Fiona Nunan and David Satterthwaite, "The Influence of Governance on the Provision of Urban Environmental Infrastructure and Services for Low-income Groups," International Planning Studies 6, no. 4 (2001): 409-426.

13. Bain, Luyendijk, and Bartram, "Universal Access to Drinking Water"; Gopalan and Rajan, "Has Foreign Aid Been Effective in the Water Supply and Sanitation Sector?"

14. Bain, Luyendijk, and Bartram, "Universal Access to Drinking Water."

15. Rudra and Jensen, "Openness and the Politics of Potable Water."

16. Matthias Krause, The Political Economy of Water and Sanitation (New York: Routledge, 2010).

17. Philip Keefer and Stephen Knack, "Why Don't Poor Countries Catch Up? A Crossnational Test of an Institutional Explanation," Economic Inquiry 35, no. 3 (1997): 590-602; Aart Kraay, Pablo Zoido-Lobaton, and Daniel Kaufmann, Governance Matters, Policy Research Working Paper No. 2196 (Washington, DC: World Bank, 1999).

18. Andrew S. Rajkumar and Vinaya Swaroop, "Public Spending and Outcomes: Does Governance Matter?” Journal of Development Economics 86, no. 1 (2008): 96111.

19. Merilee S. Grindle, "Good Enough Governance: Poverty Reduction and Reform in Developing Countries," Governance 17, no. 4 (2004): 525-548. 
20. Ibid.; Charles Oman and Christine Arndt, "Measuring Governance," Policy Brief No. 39 (Paris: Organisation for Economic Co-operation and Development [OECD], 2010).

21. Douglass C. North, Institutions, Institutional Change and Economic Performance (Cambridge: Cambridge University Press, 1990).

22. Samuel P. Huntington, Political Order in Changing Societies (New Haven: Yale University Press, 1968).

23. Amartya Sen, Development as Freedom (Oxford: Oxford University Press, 2001); Evan S. Lieberman, "The Comparative Politics of Service Delivery in Developing Countries," in Carol Lancaster and Nicolas van de Walle, eds., Oxford Handbook of Politics of Development (Oxford: Oxford University Press, 2015), ch 23.

24. Michael Mann, "Infrastructural Power Revisited," Studies in Comparative International Development 43, nos. 3-4 (2008): 355; Huntington, Political Order in Changing Societies.

25. Alexander Korolev, "Regime Responsiveness to Basic Needs: A Dimensional Approach," Studies in Comparative International Development 51, no. 4 (2016): 434 455 .

26. Halleröd et al., "Bad Governance and Poor Children."

27. Jami Nelson-Nuñez, "Substitution or Facilitation: Service-Delivery NGOs and Political Engagement in the Peruvian Amazon," Comparative Political Studies (4 June, 2018).

28. District mayor, Loreto, Peru, interviewed by Jami Nelson-Nuñez, 9 July, 2014.

29. Harold Lockwood and Stef Smits, Supporting Rural Water Supply: Moving Towards a Service Delivery Approach (Warwickshire: Practical Action, 2011), www .waterservicesthatlast.org/publications/multi_country_synthesis.

30. Peter Harvey and Bob Reed, Rural Water Supply in Africa: Building Blocks for Handpump Sustainability (Leicestershire: Water Engineering and Development Center, Loughborough University, 2004).

31. Karen Bakker, Michelle Kooy, Nur Endah Shofiani, and Ernst-Jan Martijn, special section, "Governance Failure: Rethinking the Institutional Dimensions of Urban Water Supply to Poor Households," World Development 36, no. 10 (October 2008): 1891-1915; Lockwood and Smits, Supporting Rural Water Supply; Nunan and Satterthwaite, "The Influence of Governance on the Provision of Urban Environmental Infrastructure and Services for Low-income Groups."

32. Miriam Golden and Brian Min, "Distributive Politics Around the World," Annual Review of Political Science 16, no. 1 (2013): 73-99.

33. Charles Kenny, "Measuring Corruption in Infrastructure: Evidence from Transition and Developing Countries," Journal of Development Studies 45, no. 3 (2009): 314-332; J. Edgardo Campos, Donald Lien, and Sanjay Pradhan, "The Impact of Corruption on Investment: Predictability Matters,” World Development 27, no. 6 (1999): 1059-1067.

34. Joint Monitoring Programme (JMP), “JMP Wealth Quintiles,”2015, www.wssinfo .org/documents/?tx_displaycontroller[type]=wealth_quintiles.

35. Anwar Shah, Local Governance in Developing Countries (Washington, DC: World Bank, 2006).

36. International Fund for Agricultural Development (IFAD), "Rural Sector Performance Assessments" (Rome: IFAD, 2016), www.ifad.org. 
37. Daniel Kaufmann, Aart Kraay, and Massimo Mastruzzi, "The Worldwide Governance Indicators: A Summary of Methodology, Data and Analytical Issues," Policy Research Working Paper No. 5430 (Washington, DC: World Bank, 2010), http://info .worldbank.org/governance/wgi/index.aspx\#home.

38. Monty G. Marshall, Ted Robert Gurr, and Keith Jaggers, "Polity IV Project: Political Regime Characteristics and Transitions 1800-2016" (College Park: Center for Systemic Peace, 2017).

39. David Dollar, Tatjana Kleineberg, and Aart Kraay, "Growth Still Is Good for the Poor," World Bank, Policy Research Working Paper No. 6568 (August 2013); David Dollar and Aart Kraay, "Growth Is Good for the Poor," Journal of Economic Growth 7, no. 3 (2002): 195-225; Aart Kraay, "When Is Growth Pro-poor? Evidence from a Panel of Countries," Journal of Development Economics 80, no. 1 (2006): 198-227.

40. World Bank, "World Development Indicators" (Washington, DC: Global Poverty Working Group, World Bank, 2016), http://data.worldbank.org/products/wdi.

41. Rudra and Jensen, "Openness and the Politics of Potable Water."

42. UNU-WIDER, "World Income Inequality Database WIID3.4” (UNU-WIDER, 2017), https://www.wider.unu.edu/database/world-income-inequality-database-wiid34.

43. Bain, Luyendijk, and Bartram, "Universal Access to Drinking Water."

44. OECD, "OECD.Stat” (Paris: OECD, 3 February 2014), www.oecd-ilibrary.org /content/data/data-00285-en.

45. We also ran each regression separately, with comparable results, but did not present these due to space constraints. We instead show the seemingly unrelated regressions (SUR) models, as they more accurately reflect the relationship between the error terms and provide more precise estimates. Breusch-Pagan tests were significant in every SUR analysis, indicating that the residuals of the sets of equations are nonindependent.

46. Our mean variation inflation factor (VIF) was 1.6 and no individual variable had a VIF over 2.05, which alleviates concerns of multicollinearity.

47. To ensure the robustness of our models, we also conducted tests with alternative control variables. We included the average level of gross domestic product (GDP) per capita instead of just the 1995 level. Further, we controlled for natural geographic conditions: the share of the country that is mountainous and total renewable water resources. None of these alternative specifications were significant in any model specification, nor did either of these factors change the effects of governance on drinking water access.

48. For robustness checks, we ran similar SUR models exploring the effect of World Governance Indicators on drinking water access (results can be found in the online appendix). Closely mirroring the IFAD results, all dimensions of governance except voice and accountability and stability had a positive effect on drinking water access for the rural poor. Average governance, government effectiveness, and control of corruption made a positive difference in expanding drinking water access for the poor. The rule of law mattered for all quintiles except the second richest (Q4). However, the magnitude of the effect was greater for poorer parts of the population. We are only 90 percent confident that regulatory quality made any difference for the poor, but cannot confidently say that it mattered for the wealthier groups. Stability and voice and accountability had no significant effect on any section of rural society. 